\title{
The contribution of field independence in virtual spatial updating
}

\author{
Raffaella Nori ${ }^{1}$ (D) $\cdot$ Maddalena Boccia $^{2,3} \cdot$ Massimiliano Palmiero $^{4} \cdot$ Laura Piccardi $^{2,3}$
}

Accepted: 21 April 2021 / Published online: 5 May 2021

(C) The Author(s) 2021

\begin{abstract}
Field independence (FI) is the extent to which a person perceives part of a field as discrete from the surrounding field rather than embedded in the field. Several studies proposed that it represents a cognitive style that is a relatively stable individuals' predisposition towards information processing. This study investigated the effects of Field Independence/Field Dependence (FI/FD) cognitive style on topographic memory in a virtual environment. Seventy-nine college students completed the Embedded Figure Test as a measure of FI/FD cognitive style and learned two paths in the VR-Walking Corsi Test apparatus. After the learning phase, participants had to reproduce the paths from a familiar perspective or unfamiliar perspectives. Data showed that FI cognitive style predicted the ability to reproduce a path from unfamiliar perspectives, suggesting a different impact of the angle degree. Results are discussed considering the facilitation of body axes references and the increasing difficulty due to maintaining online perspectives with higher angle degrees that increase the visuo-spatial working memory cognitive load. These results support the idea that FI predicts human navigation.
\end{abstract}

Keywords Field independence $\cdot$ Virtual reality $\cdot$ Cognitive style $\cdot$ Perspective-taking $\cdot$ Human navigation

\section{Introduction}

A common navigational task is to move through the environment in order to reach our home or to go to a known pub to meet friends or to reach a place which we never visited. To do this, we need to keep track of the changing of the spatial relations between our position and the landmarks in the environment (i.e., self-to-object relations), that is, keep in mind continuous spatial updating (Rieser 1989; Wang and Spelke 2000).

In general, the spatial updating involves two representational systems which work together: a transient sensorimotor representation, which encodes self-to-object relations (i.e., egocentric representation) and continuously updates them; and an enduring allocentric representation, which maintains

Raffaella Nori

raffaella.nori@unibo.it

1 Department of Psychology, University of Bologna, V.le Berti Pichat, 5, 40127 Bologna, Italy

2 Department of Psychology, Sapienza University of Rome, Rome, Italy

3 Cognitive and Motor Rehabilitation and Neuroimaging Unit, IRCCS Fondazione Santa Lucia, Rome, Italy

4 Department of Biotechnological and Applied Clinical Sciences, University of L'Aquila, L'Aquila, Italy object-to-object relations and stores enduring information in a preferred direction (e.g., Santoro et al. 2017a). The classic spatial updating paradigm involves acquiring the spatial location of some objects located in a room, environment or map, and then pointing to them before and after moving to a new position/orientation either physically or imaginarily (e.g., Shelton and McNamara 2004; Nori et al. 2006). Self-toobject and object-to-object spatial relations are specified in the same intrinsic reference system even if the allocentric updating requires more attentional control than egocentric updating (Mou et al. 2004). From these studies, it emerged that environmental layouts are memorized according to a preferred perspective, usually aligned with a real or an imaginary viewpoint, entailing an effect called "orientation dependence" or "alignment effect". Moreover, we can distinguish between two alignment effects: the encoding alignment effect - better performance when the imagined perspective is aligned with the perspective from which the spatial information was encoded - and the sensorimotor alignment effect, namely a better performance when the imagined perspective is aligned with the actual facing perspective (e.g., Hatzipanayioti et al. 2016). A study by Santoro, et al. (2017a) seems to indicate a relation between the two alignment effects even if other works support the independence of the effect (e.g., Avraamides and Kelly 2010). However, while a person is moving through an environment, the updating of egocentric relation occurs on line, but this updating seems to happen even when a person 
refers to an environment experienced in the past (acquired in a different moment), which is not perceptually available in a given time with the help of physical movements (e.g., Santoro et al. 2017b).

The encoding alignment effect may be reduced by increasing the familiarity with the environment (e.g., Nori and Piccardi 2011; Lopez et al. 2020a; Lopez et al. 2020b; Lopez et al. 2020c), by acting on motor, proprioceptive and vestibular information (Rossano et al., 1999; Sun et al., 2004), by manipulating the environmental features (Sholl and Nolin, 1997), such as the symmetry of the layout, the geometric structure of the enclosing space and the external cues (McNamara, 2003). Specifically, in trapezoidal, rectangular and square rooms the encoding alignment effect was reduced while it was increased in a circular room (e.g., Kelly et al. 2008; Mou et al. 2007), even for people with cognitive impairment (Caffò et al. 2018).

Furthermore, the encoding alignment effect may be more or less strong depending on how individuals acquire (directly or indirectly: Presson and Hazelrigg 1984) and retrieve the spatial knowledge. Indeed, people are quite capable of updating egocentric locations of objects as they physically rotate and translate through space (Philbeck et al. 1997; Rieser 1989), whereas egocentric updating after imagined self-motion (especially rotation) can be quite error-prone. This is also true concerning the spatial strategies used to acquire spatial information (Rossano et al. 1995; Nori et al. 2006). Indeed, even though human spatial behavior is generally assessed using overall performance levels, that is being the fastest and/or the most accurate (e.g., Nazareth et al. 2019), real-life environmental decisions are often more complex. For example, in some tasks, being fast might be advantageous (i.e., escaping from a dangerous situation), while for others it might be better to stop and think (i.e., when we do not remember a path, it could be useful to stop and think where the goal is in order to reach it). Thus, being spatial cognition situated (e.g., Palmiero et al. 2015), on the basis of context demands, more than one strategy may lead to a positive result. In other words, the dependency on context and outcome, as pointed out by a seminal publication by Witkin and Asch (1948) on cognitive style, might play a key role in the encoding alignment effect.

Cognitive style is "an individual's preferred and habitual approach to organize and represent information" (Riding and Rayner 1998, p. 8). Everybody has a distinctive cognitive style (Felder and Spurlin 2005) that influences the way in which the world is observed and processed, and as a consequence thinking, reactions and decisions are also affected (Riding and Rayner 1998, p. 118). The cognitive style affects the tasks performance as well as information retrieval and specifically the perception and organization of the surrounding space (Hayes and Allison, 1998; Piccardi et al., 2016). Several cognitive styles have been identified and each of them is stable over time, resistant to training and changes, and is independent from general intellectual ability (Ausburn and Brown 2006). Within the large body of literature, researchers have focused mainly on Field Independence (FI)/Dependence (FD) cognitive style (e.g., Guisande et al. 2007; Evans et al. 2013). According to Witkin $(1967,1977) \mathrm{FI} / \mathrm{FD}$ cognitive style involves "the extent to which the person perceives part of a field as discrete from the surrounding field as a whole, rather than embedded in the field; or the extent to which the organization of the prevailing field determines perception of its components (pp. 6-7)". FI individuals are known to rely on an internal frame of reference in dealing with environmental information, whereas FD people are known to base themselves on an external frame of reference (Witkin 1977). Even if genetic predisposition about FI/FD is still unknown, $\mathrm{X}$ chromosome has been supposed to contribute to it (Goodenough et al. 1977). FI/FD significantly affects our everyday life and modulates our performance on cognitive tasks: FD is associated with greater bias toward the global level of percept (Poirel et al. 2008) and interpersonal orientation (Witkin and Goodenough 1977); instead, FI individuals perform better than FD individuals in nearly all knowledge areas, such as language, science, arts, physical topics (Roszkowski and Snelbecker 1987; Tinajero and Páramo, 1997; Isableu et al. 1998). Most importantly for the present work, it is also noteworthy that cognitive style may predict performance on different spatial tasks (e.g., Bocchi et al. 2018; see Evans et al. 2013 for a review). Indeed, this construct determined how people acquire information from the environment and how they represent, organize and interpret spatial cues in an individual manner (Hayes and Allison, 1998).

Recently it has been suggested that FI/FD cognitive styles are pivotal in navigating complex and richly detailed environments (Evans et al., 2013). For example, FI people have been reported to handle more complex and flexible environmental representations (i.e., map-like representation) and to have a greater mental rotation ability as compared with FD (e.g., Boccia et al. 2016; Li et al. 2016; Boccia et al. 2017). Moreover, these studies have pointed out that individuals with different cognitive style on the dimension of FI/FD showed a different performance when using different frames of reference in orienting and navigating tasks. This difference could be explain considering the different way of acquiring and representing environmental information. However, to date, it is still a matter of debate how FD/FI cognitive styles influence human navigation. It is well known in the literature how one of the factors determining successful navigation is the ability to recognize routes and landmarks even from unusual perspectives (e.g., Golledge 1999), that is spatial updating. In order to attenuate or eliminate the orientation dependence, people have to perform cognitive restructuring/ updating of the learning environment.

As pointed out by Witkin and co-workers (Witkin et al., 1962), the restructuring process is based on disembedding and perspectivism abilities. Specifically, on the one hand, the 
disembedding ability allows people to memorize structural object characteristics which enabled a greater differentiation in perceptual functioning and as a consequence a better ability in recognizing objects, that is, it permits people to extract salient information from the surrounding environment. On the other hand, the perspectivism ability allows people to recognize visual perspectives other than those of the learned path, that is, it permits to adopt other people's perspective (e.g., Witkin and Goodenough 1977; Cuneo et al. 2018). It appears clear that both disembedding and perspectivism underlie the ability to perform changes of perspective and updating spatial information being typically associated with FI people (Witkin and Goodenough 1977).

Based on this evidence, the aim of the present study was to investigate the effects of FI/FD on the encoding alignment effect, after controlling for familiarity with the environment. In order to assess the encoding alignment effect, we used the virtual version of the Walking Corsi Test (WalCT) (VRWalCT: Nori et al. 2015a; Nori et al. 2015b), which is an extended version of the Corsi Block-tapping Task (Corsi, 1972), where participants are required to move to a series of places based on their memorized location. In a series of previous studies, Piccardi and co-workers demonstrated that the standard version of the WalCT measures a different spatial component (i.e., topographical memory) than the Corsi Test (e.g., Piccardi et al. 2008): the authors found that braindamaged patients affected by topographical disorientation failed on the WalCT but not on the Corsi Test (e.g., Bianchini et al. 2010). Yet, performances on WalCT significantly correlated with performance on route learning in a real environment (Piccardi et al. 2019). In addition, Cimadevilla et al. (2014) demonstrated that virtual reality-based tasks may be more accurate and useful to detect individual differences than other paper and pencil tests. Undoubtedly, the use of virtual reality has several advantages: it is less expensive and it provides a safer alternative to real-world navigation tests, which are time and space consuming (Lokka et al. 2018). Moreover, using virtual environments in assessing spatial orientation is considered realistic because the same mechanisms involved during navigation in real environments at both behavioral and neural levels are activated during navigation in a virtual environment (e.g., Regian and Yadrick 1994). The VR-WalCT (Nori et al. 2015a) reproduces a true-to-life situation in which people are required to learn spatial knowledge directly by navigating through the environment and then recall it either from the same perspective or from different ones. In this vein, when people have the possibility to learn a path without a time limit, both men and women are good at performing directional judgments irrespective of the learning orientation (e.g., Nori et al. 2015a; Nori et al. 2018): allowing longer duration of familiarization and more practice repetitions for females than males markedly reduced gender differences (e.g., Nori et al., 2018).
Specifically, we hypothesized that FI cognitive style (Witkin 1950) would reduce the encoding alignment effect as assessed by the VR-WalCT (Nori et al. 2015a; Nori et al. 2015b): FI individuals are usually more accurate and faster in perspective-taking tasks (Boccia et al. 2016; Boccia et al. 2019), due to the well-documented ability to rely on an internal frame of reference to cope with cognitive restructuring (i.e., disembedding and perspectivism). In other words, we hypothesized that FI cognitive style predicts better performance in the VR-WalCT task, especially when spatial updating is required, namely, when the spatial positions must be retrieved from a different perspective of a remote encoding path. Moreover, we hypothesized the presence of the encoding alignment effect, namely a more accurate and quicker performance in remembering the path from the learning prospective than from the others, but only for FD participants.

\section{Methods}

\section{Participants}

To determine the sample size, a power calculation was performed, using GPower 3.1. (Faul et al. 2007). To perform a multiple regression analysis (considering FI/FD cognitive styles on respectively every single dependent variable in VR-WalCT) the following parameters were used: effect size $\mathrm{f} 2=.15$ - medium magnitude; alpha $=.05$; power $=.90$. This gave a suggested sample size of 73 participants.

Seventy-nine healthy individuals $(39$ females; mean age $=$ $23.70 \pm 2.55$ years; mean education $=15.38 \pm 1.77$ years) took part in this study, $88.6 \%$ of whom were right-handed, $8.9 \%$ left-handed and 2.5\% ambidextrous (Salmaso and Longoni 1983); all had normal or corrected to normal (soft contact lenses or glasses) vision. They were recruited at the Department of Psychology of Bologna University. In a preliminary interview no participants reported previous or current neurological or psychiatric diseases. We also asked participants by a questionnaire how many times they had played videogames, in order to analyze the relationship between past experience and proficiency in the VR-WalCT (Nori et al. 2015a). The study was approved by the local Ethics Committee of the University of Bologna, and all participants gave their written informed consent to participate in accordance with the Declaration of Helsinki.

\section{Experimental Material}

\section{Embedded Figures Test (EFT; Witkin, 1950)}

Currently, the most used test to evaluate FD/FI is the EFT (source Scopus, July 2020, 776 studies that used this test). The EFT consists of a collection of cards $12.9 \times 7.7 \mathrm{~cm}$ with 
complex and simple figures. The simple figures are black and white and are formed by a single line. The complex figures are composed of a conjunction of small simple and colored figures. Each simple figure is hidden in the complex one and is not easily identifiable. The first EFT item is used to explain the test to participants. During the test phase, 12 tasks were performed. Each task started with showing a complex figure for $15 \mathrm{~s}$ and participants had to describe it during this period. Thereafter, the card with the simple figure overlapped the complex one for $10 \mathrm{~s}$. Immediately afterwards, the experimenter removed the card with the simple figure and the participant had to find its contour inside the complex figure as soon as possible, and trace it with a pencil: the experimenter recorded the response time. If the participant's response was correct, the time was recorded, whereas, if the response was wrong, the experimenter continued to clock the time until the participant reported the correct response. Participants had up to $180 \mathrm{~s}$ to provide the correct answer. The total time was computed by summing up the response times across items (12); then the result was divided by the number of items, in order to compute the overall time averaged across items: lower times indicated individuals with higher predisposition towards FI and vice versa (Witkin 1950; Witkin 1977). The embedded figure test has good test-retest reliability: indeed, the first published study of test-retest reliability (Chalip 1979) using the group version of the EFT, namely the GEFT, on 17 male and 33 female adolescents (11-16 years) on two occasions 6 months apart, showed a significant test-retest correlation of .82. This result was subsequently confirmed by Kepner and Neimark (1984), showing a test-retest correlation of .88 (after 10 days).

\section{VR-WaICT (Nori et al., 2015a, 2015b)}

The VR-WalCT was developed using an open source program, Blender (available at www.blender.org) and programmed in the Blender Game Engine to manage movements and collect experimental data. The VR-WalCT reproduced the M-WalCT (Piccardi et al., 2008) in which 18 squares $(3 \times 3 \mathrm{~cm})$ are placed on a carpet $(25 \times 60 \mathrm{~cm})$ in a scattered array. To induce route acquisition, the four cardinal points (i.e., North, South, East, West) are indicated outside the carpet. The walls are completely black (i.e. no landmark was provided). The VR-WalCT apparatus, as in Nori et al. (2015a), includes:

- an immersive helmet, Daeyangi-visor fmdfov $42,800 \times$ 600 , which was interfaced with the navigation engine by an ad-hoc module developed in Python programming language. It allows for an effective match between real head movements and virtual vision through a 6 -axis movement sensor performing a first-person experience.

- a graphic Workstation HP XW4300, Pentium4 $3.40 \mathrm{GHz}$, 2 GB RAM, Nvidia GeForce 7800 Video Card.

\section{Procedure}

Each participant was tested individually. After participants entered the experimental room they had to fill in a questionnaire aimed at gathering demographic details and they also had to respond to questions about their use of video games and undergo a brief interview about neurological or psychiatric diseases. Participants then had to complete the EFT and the VR-WalCT. The tasks order was balanced among participants.

\section{VR-WaICT - Learning Phase}

The same procedure adopted by Nori et al. (2015a) was used. Participants observed the virtual environment and used the four arrow keys/cursors to move through it. Participants were first allowed to practice with the instruments (i.e., helmet and virtual apparatus). The practical section took place in an enclosed space that was like the experimental environment; it contained four black squares to navigate through and around. When participants were ready to start the experiment, an avatar showed them an 8-step sequence by walking and stopping for $2 \mathrm{~s}$ on each square. The path was shown by the avatar in a pre-recorded video. In both environments the 2path sequences were balanced (i.e., one path started in the South and one in the North) (as in Nori et al. 2015a; Piccardi et al. 2008). In order to control the familiarization effect, as in Nori et al. (2015a, 2015b) men and women needed a different number of repetitions to learn a path. Therefore, each path was shown 3 times for men and 4 times for women. As pointed out in the introduction section, this criterion was adopted in order to be sure that participants learned the paths with the same level of accuracy in order to eliminate familiarization effect during the retrieval phase. These procedures were used for two different paths with the same level of difficulty (Nori et al. 2015a).

\section{VR-WaICT - Retrieval Phase}

As in Nori et al. (2015a), after the learning phase, participants were blindfolded and were taken to another room in which they spent $5 \mathrm{~min}$ talking with the experimenter. This procedure was used to prevent participants from mentally repeating the learned paths (e.g., De Nigris et al. 2013). Afterwards, participants were again blindfolded and taken back to the experimental room, disoriented and placed in front of the personal computer. The blindfold was then removed and in full vision, wearing the helmet, they were required to reproduce the path from a familiar perspective $\left(0^{\circ}\right.$ : the same as during the learning phase) or from unfamiliar perspectives $\left(45^{\circ}-90^{\circ}\right.$ $135^{\circ}-180^{\circ}-225^{\circ}-270^{\circ}-315^{\circ}$ : different from the learning phase perspective; Fig. 1). The order of the different perspectives was determined randomly for each path and the same order was used for all participants (as in Nori et al. 2006). For 

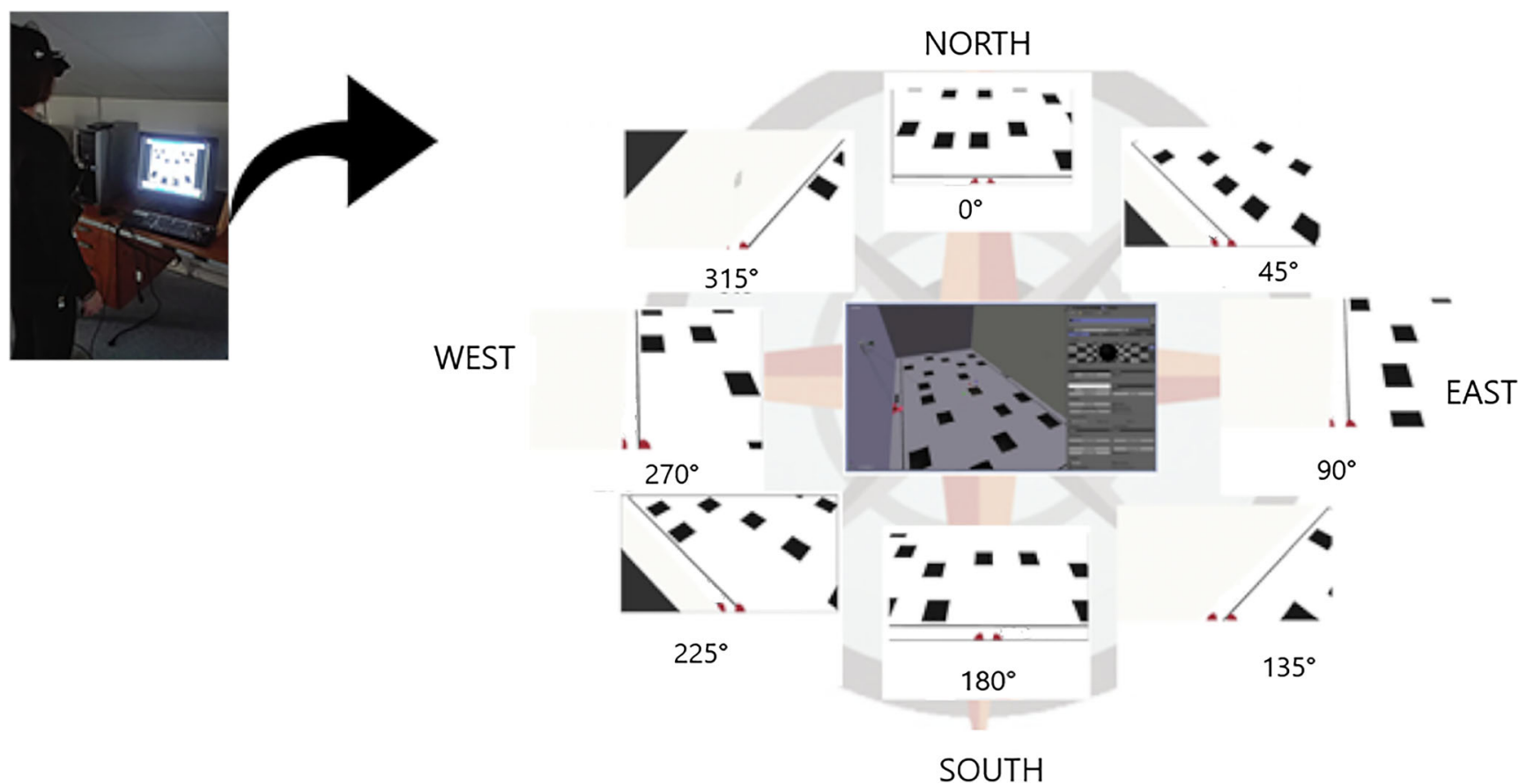

Fig. 1 Experimental setting and apparatus showing the different degrees of the path from a familiar perspective $\left(0^{\circ}\right)$ and from unfamiliar perspectives $\left(45^{\circ}-90^{\circ}-135^{\circ}-180^{\circ}-225^{\circ}-270^{\circ}-315^{\circ}\right)$

example, starting from a point of view not experienced before, participants were located at $90^{\circ}$ path perspective and were instructed to move using right/left/forward/backward in order to go to the goal. In this case participants needed to use the remote encoding path. The steps of the path correctly reproduced for each angle and time of response (s) were recorded directly by the PC program.

\section{Results}

Statistical analyses were performed using SPSS - 26 version. Both the mean number of steps correctly reported (accuracy; minimum score $=0$, maximum score $=8$ ) and the response time (s) for each degree (perspective) on the two paths were computed. Both accuracy and response time (dependent variables) were averaged for each participant.

\section{Preliminary Analysis}

Video Game Experience First of all, a series of regression analyses were performed considering how many times the participants had played video games as independent variable on the number of steps recalled correctly for each angular degree, in order to investigate possible confounding effects of this kind of practice, that is, to be sure that it did not account for some of the differences in the subsequent analyses. Results showed no significant effect $\left(0^{\circ}: \mathrm{F}_{1,77}=.01, \mathrm{r}^{2}=.00, \beta=-.01, p=.923 ; 45^{\circ}\right.$ : $\mathrm{F}_{1,77}=.10, \mathrm{r}^{2}=.00, \beta=.03, p=.742 ; 90^{\circ}: \mathrm{F}_{1,77}=.10, \mathrm{r}^{2}=.00$, $\beta=.03, p=.747 ; 135^{\circ}: \mathrm{F}_{1,77}=.02, \mathrm{r}^{2}=.00, \beta=.01, p=.869 ;$ $180^{\circ}: \mathrm{F}_{1,77}=.15, \mathrm{r}^{2}=.00, \beta=-.04, p=.697 ; 225^{\circ}: \mathrm{F}_{1,77}=.58$, $\mathrm{r}^{2}=.00, \beta=.08, p=.446 ; 270^{\circ}: \mathrm{F}_{1,77}=.41, \mathrm{r}^{2}=.00, \beta=-.07$, $p=.521 ; 315^{\circ}: \mathrm{F}_{1,77}=.51, \mathrm{r}^{2}=.00, \beta=.08, p=.476$ ).

Gender A regression analysis was also performed in order to investigate whether gender predicted FI predisposition. Gender was classified coding men as -1 and women as 1 , as suggested by Howitt and Cramer (2011). The regression model did not show any significant difference $\left(\mathrm{F}_{1,77}=2.39\right.$, $\mathrm{r}^{2}=.03, \beta=.17, p=.126$ ).

\section{Analysis on FD/FI Cognitive Style}

In order to verify whether FI cognitive style predicted the performance on perspective tasks, a series of regression analyses were performed considering the response time (s) in EFT as independent variable and respectively the mean of the number of steps correctly recalled (accuracy) and response time (s) in VR-WalCT for the eight angular degrees as dependent variables.

Accuracy Regression analysis showed that response times in EFT predicted negatively accuracy in VR-WalCT at $45^{\circ}\left(\mathrm{F}_{1}\right.$, $\left.{ }_{77}=5.22, \mathrm{r}^{2}=.06, \beta=-.25, p=.025\right), 180^{\circ}\left(\mathrm{F}_{1,77}=5.67\right.$, $\left.\mathrm{r}^{2}=.05, \beta=-.26, p=.020\right), 225^{\circ}\left(\mathrm{F}_{1,77}=4.96, \mathrm{r}^{2}=.06, \beta=\right.$ $-.24, p=.029)$ and $315^{\circ}\left(\mathrm{F}_{1,77}=8.99, \mathrm{r}^{2}=.10, \beta=-.32\right.$, $p=.004)$ degrees of rotation: individuals with higher predisposition towards FI (shorter EFT response times) showed higher accuracy on these perspectives during the retrieval 
phase. No other significant effect was shown $\left(0^{\circ}: F_{1,77}=3.21\right.$, $\mathrm{r}^{2}=.04, \beta=-.20, p=.077 ; 90^{\circ}: \mathrm{F}_{1,77}=1.67, \mathrm{r}^{2}=.02, \beta=$ $-.14, p=.200 ; 135^{\circ}: \mathrm{F}_{1,77}=1.78, \mathrm{r}^{2}=.02, \beta=-.15$, $\left.p=.186 ; 270^{\circ}: \mathrm{F}_{1,77}=2.06, \mathrm{r}^{2}=.02, \beta=-.16, p=.155\right)$.

Response Time Regression analysis showed that response times in EFT predicted positively response times in VRWalCT at $45^{\circ}\left(\mathrm{F}_{1,77}=4.39, \mathrm{r}^{2}=.05, \beta=.23, p=.039\right), 135^{\circ}$ $\left(\mathrm{F}_{1,77}=7.46, \mathrm{r}^{2}=.08, \beta=.29, p=.008\right), 180^{\circ}\left(\mathrm{F}_{1,77}=7.83\right.$, $\left.\mathrm{r}^{2}=.09, \beta=.30, p=.006\right)$ and $315^{\circ}\left(\mathrm{F}_{1,77}=6.32, \mathrm{r}^{2}=.07\right.$, $\beta=.27, p=.014)$ degrees of rotation. Again, higher levels of FI (shorter EFT response times) were associated with shorter response times in VR-WalCT at these perspectives during the retrieval phase. No other significant effect was found $\left(0^{\circ}: \mathrm{F}_{1}\right.$, ${ }_{77}=2.10, \mathrm{r}^{2}=.01, \beta=.16, p=.151 ; 90^{\circ}: \mathrm{F}_{1,77}=2.39$, $\mathrm{r}^{2}=.03, \beta=.17, \mathrm{p}=.126 ; 225^{\circ}: \mathrm{F}_{1,77}=2.08, \mathrm{r}^{2}=.05$, $\beta=.16, p=.153 ; 270^{\circ}: \mathrm{F}_{1}, 77=2.87, \mathrm{r}^{2}=.03, \beta=.19$, $p=.094)$.

\section{Angle and FI/FD Comparison}

Moreover, in order to verify the presence of alignment effect and the possible reduction caused by the performance of the FI individuals, we performed two mixed factorial ANOVAs, one for accuracy and one for response time, respectively considering cognitive style (two levels FI vs FD) as between factors and angle (8 levels) as repeated measure. In order to divide between FI and FD individuals, the median-split method was applied (median $=36.42 \mathrm{~s}$ ). This allowed to get $40 \mathrm{FI}$ individuals and $39 \mathrm{FD}$ individuals.

Accuracy The main effect "angle" was statistically significant $\left(\mathrm{F}_{7,77}=6.49, p<.001\right.$, partial $\left.{ }^{2}=.07\right)$. Bonferroni post-hoc analysis showed that participants remembered more steps when they had to recall a path from the learning perspective (i.e. $\left.0^{\circ}\right)$ than from $45^{\circ}(p=.013), 90^{\circ}(\mathrm{p}<.001), 135^{\circ}(\mathrm{p}$ $<.001), 180^{\circ}(\mathrm{p}=.039), 225^{\circ}(p=.022), 270^{\circ}(p=.027)$ and $315^{\circ}(p=.007)$. Means and standard deviations are shown in Table 1. A main effect FI/FD was revealed $\left(\mathrm{F}_{1,77}=6.58\right.$, $p=.012$, partial $\left.{ }^{2}=.07\right)$ : FI participants remembered more steps (4.19 number of steps) than FD participants did (3.25 number of steps). No other significant result was revealed (FI/ FD x angle: $\mathrm{F}_{1,77}=.82, p=.567$, partial ${ }^{2}=.01$ ).

Response Time Results showed a main effect of "angle" ( $\mathrm{F}_{7}$, ${ }_{77}=20.63, \mathrm{p}<.001$, partial ${ }^{2}=.21$ ). Bonferroni post-hoc analysis showed that remembering a path from the learning perspective $\left(0^{\circ}\right)$ was quicker than other perspectives $\left(\mathrm{p}_{\mathrm{s}}\right.$ $<.001$ ); remembering a path rotated by $45^{\circ}$ was quicker than remembering a path from $135^{\circ}(p=.005)$ and $270^{\circ}$ degrees $(p=.003)$; remembering a path rotated by $135^{\circ}$ required more time than remembering path from $225^{\circ}(p=.032)$ and $315^{\circ}$ $(\mathrm{p}=.014)$; finally, remembering a path rotated by $270^{\circ}$
Table 1 Mean and standard deviation $(S D)$ of the number of steps correctly recalled and response time are reported for each angle of rotations

\begin{tabular}{lll}
\hline Angle & Number of steps correctly recalled $(S D)$ & Response Time $(S D)$ \\
\hline $0^{\circ}$ & $4.51(.22)$ & $28.78(2.19)$ \\
$45^{\circ}$ & $3.60(.26)$ & $50.50(2.60)$ \\
$90^{\circ}$ & $3.16(.24)$ & $58.50(4.43)$ \\
$135^{\circ}$ & $3.25(.24)$ & $68.30(4.35)$ \\
$180^{\circ}$ & $3.82(.24)$ & $57.03(2.78)$ \\
$225^{\circ}$ & $3.83(.23)$ & $52.68(2.41)$ \\
$270^{\circ}$ & $3.82(.22)$ & $63.79(3.81)$ \\
$315^{\circ}$ & $3.73(.23)$ & $51.07(3.04)$ \\
\hline
\end{tabular}

required more time than remembering a path from $315^{\circ}$ $(p<.05)$. Means and standard deviations are shown in Table 1. A main effect FI/FD was revealed $\left(\mathrm{F}_{1,77}=8.91\right.$, $p=.004$, partial $\left.{ }^{2}=.10\right)$ : FI $(M=47.18$ s., S.D. $=3.13$ s. $)$ was quicker than FD $(M=60.48$ s., S.D. $=3.17$ s. $)$. No other significant result was revealed (FI/FD x angle: $\mathrm{F}_{1,77}=1.27$, $p=.263$, partial ${ }^{2}=.01$ ).

\section{Discussion}

In the present study we investigated whether FI cognitive style reduced the alignment effect in a virtual reality environment, that is the VR-WalCT, in order to better understand the contribution of individual differences in spatial updating in a virtual environment. The results partially support our hypothesis. First of all, an encoding alignment effect was revealed: remember a path from the same learning perspective was easier and quicker than the other ones supporting the presence of the well-known effect (e.g., Shelton and McNamara 2004; Nori et al. 2006). Moreover, the FI and FD behavior in solving this task was quite different both for accuracy and response time: FI are more accurate and quicker than FD individuals. Specifically, FI cognitive style predicted the ability to reproduce a path from some perspectives, but this effect did not emerge for all perspectives, suggesting a different weight depending on the angle degree.

In VR-WalCT, participants performed a task very similar to a daily situation in which they approached a familiar place from an unusual perspective. When we walk through a real or virtual environment, we continually change our perspective, which requires a continuous updating of our position in the new orientation (e.g., a turning) (Wang and Spelke 2000), so it is essential to remember a remote path acquired from a specific point of view, compare the old layout with the new perspective and update it. This updating is automatic (e.g., Shollet al. 2006) and involves computing the amplitude of angular displacements. Self-to-landmark updating takes place 
in an egocentric frame of reference, with the body's axis of orientation serving as the reference axis relative to which the spatial coordinates of the egocentric vectors are updated (Sholl et al. 2006). Recently, Avraamides, et al. (2013) argued that the self-to-object relations - namely, egocentric representation - are automatically computed during perspective-taking. Thus, in order to face misaligned perspectives, people need to suppress these relations: in some cases, this suppression is easy to perform, while in others it is more difficult. Specifically, it is quite easy to suppress misaligned information from some perspectives (i.e., $90^{\circ}, 135^{\circ}, 270^{\circ}$ ) that correspond to body axes $\left(90^{\circ}\right.$ corresponded to the right and $270^{\circ}$ corresponded to the left) or close to them $\left(135^{\circ}\right.$ is near to the right), while it is much more difficult to suppress them from perspectives not corresponding to body axes (i.e., $45^{\circ}, 225^{\circ}$, $315^{\circ}$ ) or when a complete change of perspective is required $\left(180^{\circ}\right)$, that is behind them. When different perspectives correspond to body axes or are close to them, individuals do not make errors in performing the task, whereas when the perspectives are far away from the body axes only individuals with FI predisposition are advantaged. In particular, FI individuals remember a greater number of steps compared to FD individuals. Very likely, when perspectives are completely misaligned from the learning point of view, an additional visuo-spatial working memory load makes the task much more difficult. Indeed, when the individual's point of view of the display changes, an active updating of both the mental representation of the display and the individual's position in the environment is necessary, and as a consequence the working memory load increases (Coluccia and Louse 2004). However, we can suppose that disembedding and perspectivism skills characterizing FI predisposition may facilitate the perspective-taking task. FI individuals are more likely to use internal cues and to be selective in the information input, so that their performance is less likely to be influenced by the image rotation experience engendered by the change of perspective, while FD individuals rely more on external cues and have difficulty in separating input information from contextual surroundings, resulting in more difficulties with mental rotation tasks. This is true specifically for the spatial information located behind us, out of the body axes, namely right and left. Moreover, as suggested by Witkin and Goodenough (1977), FD individuals tend to maintain the structure of the field as it is presented, whereas FI individuals tend to impose their own structure of the field.

The present study indicates that individuals with different inclination within the dimension of field dependenceindependence show different performance in recalling a path from different points of view in a virtual environment. This difference may due to their different bearing on the perception, acquisition and processing of environmental information, which in turn causes different ways of orienting themselves in the environment ( $\mathrm{Li}$ et al. 2016). As pointed out by $\mathrm{Li}$ et al.
(2016), FD individuals may use the ego-centered frame of reference to acquire and represent environmental layout. Therefore, they have to align their own frame of reference with the world-centered frame of reference when performing a perspective change task, a process where more errors could be made and more time is needed to respond. FI individuals, on the other hand, may use the world-centered frame of reference when they acquire and represent the environment. Therefore, FI individuals could easily adjust their frame of reference, with higher accuracy and less time in changing perspective.

These results are supported by Boccia et al. (2017). In their study, FI predicted the individual's spatial strategies used to acquire and represent the environment. They found that FI is associated with better performance on map-like knowledge that requires representing the environment in spite of their own position. Thus, the more visually independent the individuals are, the more spatial information there will be in their cognitive map. Taking into consideration the Cumulative Model of Spatial knowledge (Siegel and White 1975) FI individuals should tend to use a global map-like representation of the environment, that is to say the highest level of spatial knowledge. The difficulty in solving perspective-taking tasks by FD is also supported by the time FD individuals spend in changing perspectives: FD individuals employ more time to break free from their egocentric perspective, even if the more time spent in performing the task is not predictive of a good performance in recalling the path. To sum up, our results suggest that performance in perspective-taking tasks and more in general in spatial updating depends on the cognitive style: FI individuals probably rely on internal frame references that make them better navigators.

Acknowledgments The authors wish to thank Massimo Montanari and Laura Lugli for their help in collecting data.

Open Practices Statement The data and materials of all the experiments are available upon request.

Author Contributions RN and LP designed and conceived the study. MP and MB collected the data. MP and MB analyzed the data, and RN and LP wrote a first draft of the manuscript, which was further revised by all the authors. All the authors contributed to the discussion of the results.

Funding Open access funding provided by Alma Mater Studiorum Università di Bologna within the CRUI-CARE Agreement.

\section{Declarations}

Conflict of Interest The authors do not have any conflicts of interest to declare.

Open Access This article is licensed under a Creative Commons Attribution 4.0 International License, which permits use, sharing, adaptation, distribution and reproduction in any medium or format, as long as 
you give appropriate credit to the original author(s) and the source, provide a link to the Creative Commons licence, and indicate if changes were made. The images or other third party material in this article are included in the article's Creative Commons licence, unless indicated otherwise in a credit line to the material. If material is not included in the article's Creative Commons licence and your intended use is not permitted by statutory regulation or exceeds the permitted use, you will need to obtain permission directly from the copyright holder. To view a copy of this licence, visit http://creativecommons.org/licenses/by/4.0/.

\section{References}

Ausburn, L. J., \& Brown, D. (2006). Learning strategy patterns \& instructional preferences of career \& technical education students. Journal of Industrial Teacher Education, 43(4), 1-27.

Avraamides, M. N., \& Kelly, J. W. (2010). Multiple systems of spatial memory: Evidence from described scenes. Journal of Experimental Psychology: Learning Memory \& Cognition, 36(3), 635-645. https://doi.org/10.1037/a0017040.

Avraamides, M. N., Theodorou, M., Agathokleous, A., \& Nicolaou, A. (2013). Revisiting perspective-taking: Can people maintain imagined perspectives? Spatial Cognition and Computation, 13(1), 5078. https://doi.org/10.1080/13875868.2011.639915.

Bianchini, F., Incoccia, C., Palermo, L., Piccardi, L., Zompanti, L., Sabatini, U., Peran, P., \& Guariglia, C. (2010). Developmental topographical disorientation in a healthy subject. Neuropsychologia, 48(6), 1563-1573. https://doi.org/10.1016/j.neuropsychologia. 2010.01 .025

Bocchi, A., Giancola, M., Piccardi, L., Palmiero, M., Nori, R., \& D'Amico, S. (2018). How would you describe a familiar route or put in order the landmarks along it? It depends on your cognitive style! Experimental Brain Research, 236, 3121-3129. https://doi. org/10.1007/s00221-018-5367-3.

Boccia, M., Piccardi, L., D'Alessandro, A., Nori, R., \& Guariglia, C. (2017). Restructuring the navigational field: Individual predisposition towards field independence predicts preferred navigational strategy. Experimental Brain Research, 235(6), 1741-1748. https://doi.org/10.1007/s00221-017-4936-1.

Boccia, M., Piccardi, L., Di Marco, M., Pizzamiglio, L., \& Guariglia, C. (2016). Does field independence predict visuo-spatial abilities underpinning human navigation? Behavioural evidence. Experimental Brain Research, 234(10), 2799-2807. https://doi.org/10.1007/ s00221-016-4682-9.

Boccia, M., Vecchione, F., Di Vita, A., D’Amico, S., Guariglia, C., \& Piccardi, L. (2019). Effect of cognitive style on topographical learning across life span: Insights from normal development. Child Development, 90(2), 462-470. https://doi.org/10.1111/cdev.13184.

Caffò, A. O., Lopez, A., Spano, G., Serino, S., Cipresso, P., Stasolla, F., Savino, M., Lancioni, G. E., Riva, G., \& Bosco, A. (2018). Spatial reorientation decline in aging: The combination of geometry and landmarks. Aging and Mental Health, 22, 1372-1383. https://doi. org/10.1080/13607863.2017.1354973.

Chalip, L. (1979). Learning on the group embedded figures test. Perceptual and Motor Skills, 48, 1070. https://doi.org/10.2466/ pms.1979.48.3c.1070.

Cimadevilla, J. M., Lizana, J. R., Roldán, M. D., Cánovas, R., \& Rodríguez, E. (2014). Spatial memory alterations in children with epilepsy of genetic origin or unknown cause. Epileptic Disorders, 16(2), 203-207. https://doi.org/10.1684/epd.2014.0661.
Coluccia, E., \& Louse, G. (2004). Gender differences in spatial orientation: A review. Journal of Environmental Psychology, 24, 329-340. https://doi.org/10.1016/j.jenvp.2004.08.006.

Corsi, P. M. (1972). Human memory and the medial temporal region of the brain (Ph.D.). McGill University.

Cuneo, F., Antonietti, J.-P., \& Mohr, C. (2018). Unkept promises of cognitive styles: A new look at old measurements. PLoS One, 13(8), e0203115. https://doi.org/10.1371/journal.pone.0203115.

De Nigris, A., Piccardi, L., Bianchini, F., Palermo, L., Incoccia, C., \& Guariglia, C. (2013). Role of visuo-spatial working memory on navigational disorders in neglect. Cortex, 49(4), 920-930. https:// doi.org/10.1016/j.cortex.2012.03.009.

Evans, C., John Richardson, J. T. E., \& Waring, M. (2013). Field independence: Reviewing the evidence. British Journal of Educational Psychology, 83(2), 210-224. https://doi.org/10.1111/bjep.12015.

Faul, F., Erdfelder, E., Lang, A. G., \& Buchner, A. (2007). G*power 3: A flexible statistical power analysis program for the social, behavioral, and biomedical sciences. Behavior Research Methods, 39, 175-191. https://doi.org/10.3758/BF03193146.

Felder, R. M., \& Spurlin, J. (2005). Applications, reliability and validity of the index of learning styles. International Journal of Engineering Education, 21, 103-112.

Golledge, R. G. (1999). Wayfinding behavior: Cognitive mapping and other spatial processes. Baltimore, MD: Johns Hopkins University Press.

Goodenough, D. R., Gandini, E., Olkin, I., Pizzamiglio, L., Thayer, D., \& Witkin, H. A. (1977). A study of X chromosome linkage with field dependence and spatial visualization. Behavior Genetics, 7, 373287. https://doi.org/10.1007/BF01077450.

Guisande, M. A., Paramo, M. F., Tinajero, C., \& Almeida, L. S. (2007). Field dependence-independence (FDI) cognitive style: An analysis of attentional functioning. Psicothema, 19, 572-577.

Hatzipanayioti, A., Galati, A., \& Avraamides, M. N. (2016). The protagonist's first perspective influences the encoding of spatial information in narratives. Quarterly Journal of Experimental Psychology, 69(3), 506-520. https://doi.org/10.1016/10.1080/17470218.2015. 1056194.

Hayes, J., \& Allison, C. W. (1998). Cognitive style and its relevance for management practice. British Journal of Management, 5(1), 53-71. https://doi.org/10.1111/j.1467-8551.1994.tb00068.x.

Howitt, D., \& Cramer, D. (2011). Introduction to SPSS statistics in psychology: For version 19 and earlier. Prentice Hall.

Isableu, B., Ohlmann, T., Cremieux, J., \& Amblard, B. (1998). How dynamic visual field dependence-independence interacts with the visual contribution to postural control. Human Movement Science, 17(3), 367-391. https://doi.org/10.1016/S0167-9457(98)00005-0.

Kelly, J. W., McNamara, T. P., Bodenheimer, B., Carr, T. H., \& Rieser, J. J. (2008). The shape of human navigation: How environmental geometry is used in maintenance of spatial orientation. Cognition, 109, 281-286. https://doi.org/10.1016/j.cognition.2008.09.001.

Kepner, M. D., \& Neimark, E. D. (1984). Test-retest reliability and differential patterns of score change on the group embedded figures test. Journal of Personality and Social Psychology, 46(6), 14051413. https://doi.org/10.1037/0022-3514.46.6.1405.

Li, H., Zhangb, Y., Wub, C., \& Mei, D. (2016). Effects of field dependence-independence and frame of reference on navigation performance using multi-dimensional electronic maps. Personality and Individual Differences, 97, 289-299. https://doi.org/10.1016/j.paid. 2016.03.078.

Lokka, I. E., Çöltekin, A., Wiener, J., Fabrikant, S. I., \& Röcke, C. V. (2018). Virtual environments as memory training devices in navigational tasks for older adults. Scientific Reports, 8, 10809. https://doi. org/10.1038/s41598-018-29029-x. 
Lopez, A., Caffò, A. O., \& Bosco, A. (2020a). Memory for familiar locations: The impact of age, education and cognitive efficiency on two neuropsychological allocentric tasks. Assessment, 27, 1588-1603. https://doi.org/10.1177/1073191119831780.

Lopez, A., Caffò, A. O., Tinella, L., Postma, A., \& Bosco, A. (2020c). Studying individual differences in spatial cognition through differential item functioning analysis. Brain Sciences, 10(774), 1-16. https://doi.org/10.3390/brainsci10110774.

Lopez, A., Postma, A., \& Bosco, A. (2020b). Categorical \& coordinate spatial information: Can they be disentangled in sketch maps? Journal of Environmental Psychology, 68, 101392. https://doi.org/ 10.1016/j.jenvp.2020.101392.

McNamara, T. P. (2003). How are the locations of objects in the environment represented in memory? In C. Freksa, W. Brauer, C. Habel, and K. F. Wender (Eds.), Spatial cognition III. Lecture notes in computer science (2685, pp. 174-191).

Mou, W., McNamara, T. P., Valiquette, C. M., \& Rump, B. (2004). Allocentric and egocentric updating of spatial memories. Journal of Experimental Psychology: Learning, Memory, and Cognition, 30, 142-157. https://doi.org/10.1037/0278-7393.30.1.142.

Mou, W., Zhao, M., \& McNamara, T. P. (2007). Layout geometry in the selection of intrinsic frames of reference from multiple viewpoints. Journal of Experimental Psychology: Learning Memory and Cognition, 33, 145-154. https://doi.org/10.1037/0278-7393.33.1. 145

Nazareth, A., Huang, X., Voyer, D., \& Newcombe, N. (2019). A metaanalysis of sex differences in human navigation skills. Psychonomic Bulletin and Review, 26, 1503-1528. https://doi.org/10.3758/ s13423-019-01633-6.

Nori, R., Grandicelli, S., \& Giusberti, F. (2006). Alignment effect: Primary secondary learning and cognitive styles. Perception, 35(9), 1233-1249. https://doi.org/10.1068/p5351.

Nori, R., \& Piccardi, L. (2011). Familiarity and spatial cognitive style: How important are they for spatial representation? In J. B. Thomas (Ed.), Spatial memory: Visuospatial processes, cognitive performance and developmental effects (pp. 123-144). NovaPublisher.

Nori, R., Piccardi, L., Maialetti, A., Goro, M., Rossetti, A., Argento, O., \& Guariglia, C. (2018). No gender differences in egocentric and allocentric environmental transformation after compensating for male advantage by manipulating familiarity. Frontiers in Neuroscience, 12, 204. https://doi.org/10.3389/fnins.2018.00204.

Nori, R., Piccardi, L., Migliori, M., Guidazzoli, G., Frasca, F., De Luca, D., \& Giusberti, F. (2015a). The virtual reality walking Corsi test. Computers in Human Behavior, 48, 72-77. https://doi.org/10.1016/ j.chb.2015.01.035.

Nori, R., Piccardi, L., Pelosi, A., De Luca, D., Frasca, F., \& Giusberti, F. (2015b). Perspective changing in WalCT and VR-WalCT: A gender difference study. Computers in Human Behavior, 53, 316-323. https://doi.org/10.1016/j.chb.2015.07.015.

Palmiero, M., Nori, R., Rogolino, C., D’Amico, S., \& Piccardi, L. (2015). Situated navigational working memory: The role of positive mood. Cognitive Processing, 16(1), 327-330. https://doi.org/10.1007/ s10339-015-0670-4.

Philbeck, J. W., Loomis, J. M., \& Beall, A. C. (1997). Visually perceived location is an invariant in the control of action. Perception \& Psychophysics, 59, 601-612. https://doi.org/10.3758/BF03211868.

Piccardi, L., De Luca, M., Nori, R., Palermo, L., Iachini, F., \& Guariglia, C. (2016). Navigational style influences eye movement pattern during exploration and learning of an environmental map. Frontiers in Behavioral Neuroscience, 10, 140. https://doi.org/10.3389/fnbeh. 2016.00140 .

Piccardi, L., Iaria, G., Ricci, M., Bianchini, F., Zompanti, L., \& Guariglia, C. (2008). Walking in the Corsi test: Which type of memory do you need? Neuroscience Letters, 432(2), 127-131. https://doi.org/10. 1016/j.neulet.2007.12.044.

Piccardi, L., Palmiero, M., Bocchi, A., Boccia, M., \& Guariglia, C. (2019). How does environmental knowledge allow us to come back home? Experimental Brain Research, 237(7), 1811-1820. https:// doi.org/10.1007/s00221-019-05552-9.

Poirel, N., Pineau, A., Jobard, G., \& Mellet, E. (2008). Seeing the forest before the trees depends on individual field-dependency characteristics. Experimental Psychology, 55(5), 328-333. https://doi.org/10. 1027/1618-3169.55.5.328.

Presson, C. C., \& Hazelrigg, M. D. (1984). Building spatial representations through primary and secondary learning. Journal of Experimental Psychology: Learning, Memory, and Cognition, 10(4), 716-722. https://doi.org/10.1037/0278-7393.10.4.716.

Regian, J. W., \& Yadrick, R. M. (1994). Assessment of configurational knowledge of naturally- and artificially-acquired large-scale space. Journal of Environmental Psychology, 14(3), 211-223. https://doi. org/10.1016/S0272-4944(94)80057-X.

Riding, R., \& Rayner, S. (1998). Cognitive styles and learning strategies. David Fulton Publishers.

Rieser, J. J. (1989). Access to knowledge of spatial structure at novel points of observation. Journal of Experimental Psychology: Learning, Memory, and Cognition, 15(6), 1157-1165. https://doi. org/10.1037/0278-7393.15.6.1157.

Rossano, M. J., Warren, D. H., \& Kenan, A. (1995). Orientation specificity: How general is it? American Journal of Psychology, 108, 359-380. https://doi.org/10.2307/1422895.

Rossano, M. J., West, S. O., Robertson, T. J., Wayne, M. C., \& Chase, R. B. (1999). The acquisition of route and survey knowledge from computer models. Journal of Environmental Psychology, 19(2), 101-115. https://doi.org/10.1006/jevp.1998.0115.

Roszkowski, M. J., \& Snelbecker, G. E. (1987). Peripheral laterality, field independence, and academic achievement. A re-examination of their interrelationship. Developmental Neuropsychology, 3, 53-65. https://doi.org/10.1080/87565648709540363.

Salmaso, D., \& Longoni, A. M. (1983). Hand preference in an Italian sample. Perceptual and Motor Skills, 57, 1039-1042. https://doi. org/10.2466/pms.1983.57.3f.1039.

Santoro, I., Murgia, M., Sors, F., \& Agostini, T. (2017b). Walking reduces the gap between encoding and sensorimotor alignment effects in spatial updating of described environments. Quarterly Journal of Experimental Psychology, 70(4), 750-760. https://doi.org/10.1080/ 17470218.2016.1157615.

Santoro, I., Murgia, M., Sors, F., Prpic, V., \& Agostini, T. (2017a). Walking during the encoding of described environments enhances a heading-independent spatial representation. Acta Psychologica, 180, 16-22. https://doi.org/10.1016/j.actpsy.2017.08.002.

Shelton, A. L., \& McNamara, T. P. (2004). Orientation and perspective dependence in route and survey learning. Journal of Experimental Psychology: Learning Memory and Cognition, 30(1), 158-170. https://doi.org/10.1037/0278-7393.30.1.158.

Sholl, M. J., Kenny, R. J., \& DellaPorta, K. A. (2006). Allocentricheading recall and its relation to self-reported sense-of-direction. Journal of Experimental Psychology: Learning Memory and Cognition, 32(3), 516-533. https://doi.org/10.1037/0278-7393.32. 3.516.

Sholl, M. J., \& Nolin, T. L. (1997). Orientation specificity in representations of place. Journal of Experimental Psychology: Learning Memory and Cognition, 23(6), 1494-1507. https://doi.org/10. 1037/0278-7393.23.6.1494.

Siegel, A. W., \& White, S. H. (1975). The development of spatial representations of large-scale environments (vol 10). Academic Press. 
Sun, H.-J., Campos, J. L., \& Chan, G. S. W. (2004). Multisensory integration in the estimation of relative path length. Experimental Brain Research, 154(2), 246-254. https://doi.org/10.1007/s00221-003$1652-9$.

Tinajero, C., \& Páramo, M. F. (1997). Field dependence-independence and academic achievement: A re-examination of their relationship. British Journal of Educational Psychology, 67(2), 199-212. https:// doi.org/10.1111/j.2044-8279.1997.tb01237.x.

Wang, R. F., \& Spelke, E. S. (2000). Updating egocentric representations in human navigation. Cognition, 77(3), 215-250. https://doi.org/10. 1016/S0010-0277(00)00105-0.

Witkin, H. A. (1950). Individual differences in ease of perception of embedded figures. Journal of Personality, 19(1), 1-15. https://doi. org/10.1111/j.1467-6494.1950.tb01084.x.

Witkin, H. A. (1967). A cognitive-style approach to cross-cultural research. International Journal of Psychology, 2(4), 233-250. https://doi.org/10.1080/00207596708247220.
Witkin, H. A. (1977). Cognitive style in personal and cultural adaption. Field-dependent and field-independent cognitive styles and their educational implications. Clark University Press.

Witkin, H. A., \& Asch, S. E. (1948). Studies in space orientation: IV. Further experiments on perception of the upright with displaced visual field. Journal of Experimental Psychology, 38, 762-782. https://doi.org/10.1037/h0053671.

Witkin, H. A., Dyk, R. B., Faterson, H. F., Goodenough, D. R., \& Karp, S. A. (1962). Psychological differentiation. Wiley.

Witkin, H. A., \& Goodenough, D. R. (1977). Field dependence and interpersonal behavior. Psychological Bulletin, 84(4), 661-689. https://doi.org/10.1037/0033-2909.84.4.661.

Publisher's Note Springer Nature remains neutral with regard to jurisdictional claims in published maps and institutional affiliations. 